\title{
Spirometric reference values in a large Middle Eastern population
}

\author{
M. Golshan*, M. Nematbakhsh", B. Amra*, R.O. Crapo"
}

Spirometric reference values in a large Middle Eastern population. M. Golshan, M. Nematbakhsh, B. Amra, R.O. Crapo. (C) ERS Journals Ltd 2003.

ABSTRACT: Ethnic differences in pulmonary function have been frequently reported. The purposes of this study were to derive equations for the prediction of normative spirometry values for a large population of Persians in Isfahan and compare them to reference values from a White Euro-USA population.

Spirometry measurements were obtained from 4,341 randomly selected healthy nonsmoker subjects in Isfahan, Iran, utilising American Thoracic Society guidelines and a vigorous quality assurance program. Measured data from 3,213 subjects were analysed using multiple regression techniques to derive prediction equations for spirometric variables; the remaining 1,128 subjects were used as a control group to test the validity of the derived equations. In addition, predicted values were compared with values derived from recently published equations for the USA.

Derived prediction equations showed good performance for most spirometric parameters. Compared with USA Whites, adult Persians have minimally lower forced vital capacities, while the values for children are close to USA Whites.

In comparison with reference equations based on European or USA populations, local reference values are more biologically and technically suitable for the interpretation of spirometric data from Iranian populations.

Eur Respir J 2003; 22: 529-534.

\begin{abstract}
*Dept of Medicine and "Dept of Physiology, Isfahan University of Medical Sciences, Isfahan, Iran, University of Utah and LDS Hospital Pulmonary Division, LDS Hospital, Salt Lake City, USA.
\end{abstract}

Correspondence: M. Golshan, Dept of Medicine, Isfahan University of Medical Sciences, PO Box 81655-755, Isfahan, Iran. Fax: 983112228204

E-mail: golshan@med.mui.ac.ir

Keywords: Iran

Isfahan

lung function tests normative values reference equations spirometry

Received: January 122003

Accepted after revision: April 212003
Spirometry is pivotal in screening, diagnosing and monitoring respiratory disease and is increasingly advocated for use in primary care practice [1]. Most pulmonary function laboratories in the USA and Europe use reference values based on populations with predominantly European backgrounds [2-4]. However, studies have demonstrated ethnic differences in pulmonary function [5-7], and prediction equations based on European populations may not perform well on other populations. Differences in spirometric findings have been attributed, at least in part, to anthropometric differences. For example, compared to Blacks, Whites tend to have slightly larger trunks and shorter legs (i.e. larger trunkto-leg ratio) at a given height $[7,8]$, corresponding to vital capacities that are larger by $10-15 \%$ for a given standing height [3]. Ethnic differences in lung function have also been suggested for many other groups [5, 7, 9], specifically Asians $[6,10-12]$. There is a lack of information concerning spirometric reference values for people living in the Middle East. The current authors studied a large group of healthy people living in Isfahan, Iran to derive spirometric reference values.

\section{Subjects and methods}

The Institutional Review Board for medical ethics at Isfahan Medical School, Iran approved the research protocol. During a 5-yr period from 1997 to October 2001, volunteer medical students, officers of a bank referred for checkup and every 20th patient of a general medical clinic in Isfahan, Iran were invited to bring their family members (parents, spouse, and children) for medical evaluation including a meticulous medical history, physical examination and spirometry. The exclusion criteria were: respiratory complaints, history of ever smoking regularly, history of serious pulmonary disease, physical findings suggesting cardiopulmonary disease and evident chest deformity. Subjects were included in the study if they did not meet any of the exclusion criteria. Height was measured to the nearest centimetre. Subjects were measured without shoes, standing against a wall (buttocks, back, and head against the wall) with their head erect in the Frankfort horizontal plane. A carpenter's square was placed against the wall and head, the subject was asked to step away from the wall, and height was measured from the floor to the bottom of the square with a metal rule attached to the wall. Age was obtained by asking the subjects. In most cases, insurance cards, or identity documents were checked and confirmed the accuracy of the stated age.

Spirometry was performed using one of two electronic flow-type pneumotachometer spirometers of the same model (Moose PFT system; Cybermedic, Louisville, CO, USA, software version $3.8 \mathrm{D}$ ) with the patient sitting, wearing a nose clip. The spirometers were calibrated daily with a $3 \mathrm{~L}$ syringe (Hans Rudolph Inc., Kansas City, MO, USA). After the study, the calibration syringes were compared to a new, certified, calibration syringe; both were accurate to within $0.13 \%$ of $3000 \mathrm{~mL}$. Barometric pressures, measured daily by Isfahan airport, showed a range from $632-635 \mathrm{mmHg}$. Room temperature was monitored using a Brooklyn NIST Centigrade thermometer (Brooklyn Thermometer, Farmingdale, NY) and kept between $21-25^{\circ} \mathrm{C}$. Spirometry results were automatically corrected to body temperature and ambient pressure, and saturated with water vapour conditions by spirometer software. Two experienced technicians in accordance with American Thoracic Society guidelines [13] tested the subjects. Spirograms were repeated until three acceptable 
tests were obtained. Studies were considered acceptable if the largest and second largest values for forced vital capacity (FVC) and forced expiratory volume in one second (FEV1) were within $200 \mathrm{~mL}$ of each other [13]. If the first manoeuvres were not satisfactory, further manoeuvres were obtained until the reproducibility criteria were satisfied or 8 manoeuvres were obtained. Agreement between the two sets of spirometers and technicians was frequently checked by randomly repeating one test with each technician/instrument combination.

The largest FVC, FEV1, and peak expiratory flow (PEF) from any acceptable test were recorded for each subject. Other flows including the forced expiratory flow from $25-75 \%$ of the vital capacity (FEF25-75\%) and instantaneous expiratory flows at $25 \%, 50 \%$ and $75 \%$ of FVC (FEF25, FEF50, and FEF75) were derived from the single "best" test defined as the manoeuvre with the largest sum of FVC and FEV1.

\section{Data analysis}

Since lung function data from males and females were significantly different, regression analyses were applied to each sex separately. The relationships between lung volumes and anthropometric variables were examined first. Various regression models including quadratic, power functions, logtransformed and linear relationships were compared. For all lung indices examined, simple linear models provided more acceptable fits to the data if the data were subdivided into two age categories: $\leqslant 20$ yrs, $>20$ yrs. Therefore, linear models were chosen as the basic format for evaluating the relationships between the dependent variables and the independent variables. The change of the slope of FEV1 at age 20 is seen in figure 1.

Approximately three quarters of the cases were randomly selected for the development of prediction equations. The remaining cases were used as a control group to validate the derived equations. Data were analysed by stepwise multiple regression techniques. Dependent variables (FVC, FEV1, FEV1/FVC, PEF, FEF25, FEF50, FEF75, and FEF25-75) were regressed against height and age in different sex and age categories. They were first regressed individually against height and age. Stepwise multiple regression analyses were then used to determine which combination of variables would best fit the model. Predictor variables were retained in the regression model only if they significantly improved the

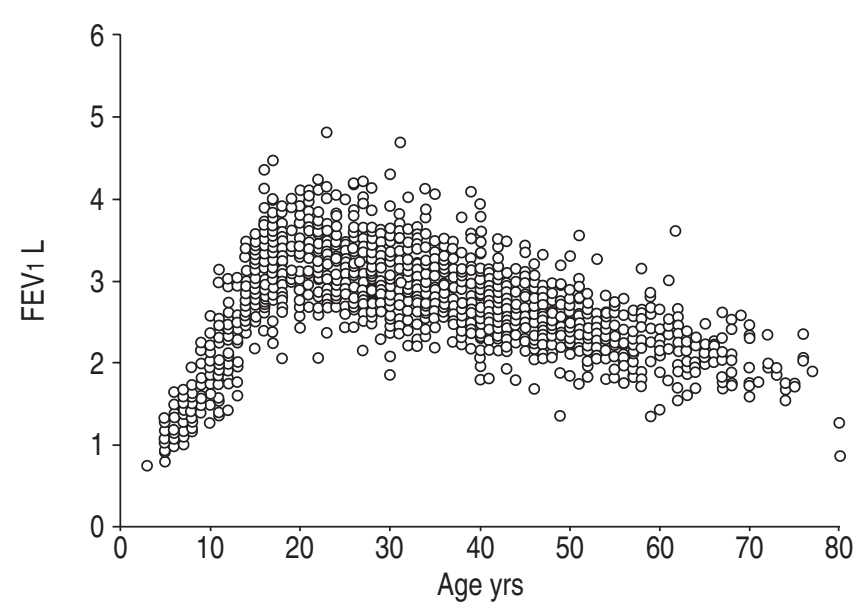

Fig. 1.-Scatter plot of female forced expiratory volume in one second $\left(\mathrm{FEV}_{1}\right)$ against age showing the marked change at around age $20 \mathrm{yrs}$. explained variance of the dependent variable. The equations with the lowest standard errors of estimate and highest coefficients of determination $\left(\mathrm{r}^{2}\right)$ were considered acceptable, if each included variable contributed significantly to the model $(p<0.05)$. Lower limits of normal range were calculated as the lower fifth percentile of the distribution of the residuals from each equation.

Data from the control group were used to evaluate the validity of the derived equations as follows. Using the derived equations, predicted values were calculated for each control subject and compared with their measured values. Paired sample t-tests were used to compare the means of each set of measured and predicted values. The level of significance was set at $\mathrm{p}<0.01$ to account for the multiple comparisons.

The performance of the equations used in the current study were also compared, with the equations based on a random sample of the general population of the USA, published by HANKINSON et al. [14]. Using the control subjects of the current study, predicted values were calculated for each individual with the equations used in the current study, and the equations of HANKINSON et al. [14]. Means and SD of both sets of predicted values were calculated for each spirometric variable in each age and sex grouping and the results were compared using the same tests.

Repeat tests were performed on 342 subjects to assess test

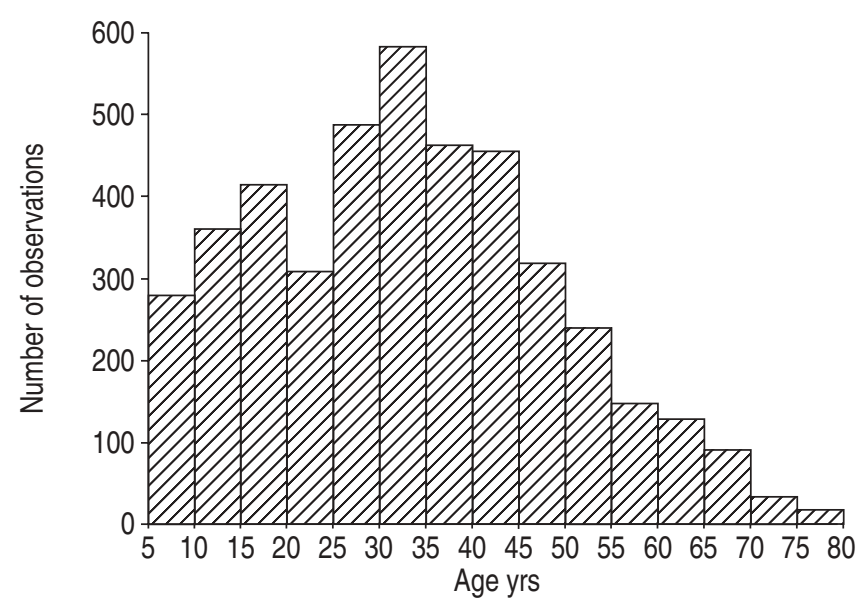

Fig. 2.-Frequency distribution of age for the included study subjects.

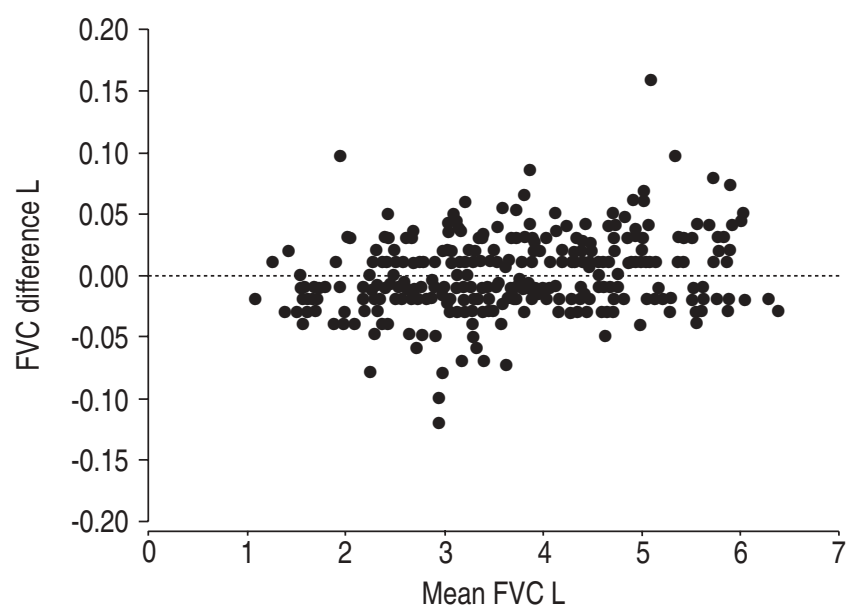

Fig. 3.-Bland-Altman [15] plot of the differences between the first and second forced vital capacity (FVC) measurements in subjects selected for repeat studies. Differences are plotted against mean FVC. No systematic differences were observed. 
Table 1.-Anthropometric characteristics of the two subgroups of subjects

\begin{tabular}{|c|c|c|c|c|}
\hline \multirow[t]{2}{*}{ Characteristic } & \multicolumn{2}{|c|}{ Main group } & \multicolumn{2}{|c|}{ Control group } \\
\hline & $<21 \mathrm{yrs}$ & $\geqslant 21 \mathrm{yrs}$ & $<21$ yrs & $\geqslant 21 \mathrm{yrs}$ \\
\hline Female subjects & 310 & 1110 & 128 & 387 \\
\hline Male subjects & 491 & 1302 & 192 & 421 \\
\hline Range of female age & 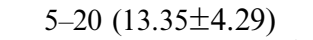 & $21-80(41.45 \pm 12.44)$ & 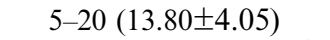 & $21-80(39.51 \pm 11.95)$ \\
\hline Range of female height & $93-174(146.25 \pm 17.47)$ & $139-194(156.30 \pm 5.92)$ & $102-171(147.87 \pm 16.98)$ & $140-171(156.37 \pm 5.51)$ \\
\hline Range of male age ${ }^{\#}$ & $5-20(12.86 \pm 4.36)$ & $21-82(38.50 \pm 12.28)$ & 5-20 (13.43土4.39) & $21-82(37.57 \pm 12.10)$ \\
\hline Range of male height & $93-190(148.17 \pm 22.41)$ & $144-196(171.10 \pm 6.60)$ & $111-192(150.91 \pm 22.22)$ & $147-192(171.31 \pm 6.88)$ \\
\hline
\end{tabular}

Data are presented as mean \pm SD. ${ }^{\#}$ : ages are in years; ${ }^{\top}$ : heights are in $\mathrm{cm}$.

repeatability between the two technician, instrument sets. The agreement between the original and the repeated FVC measurements was estimated as the SE of the mean differences between the first and second parameters. The differences were displayed in a Bland Altman plot [15].

\section{Results}

Of the 6,424 subjects initially invited for interview and spirometry, 2,083 were excluded for various reasons, including: history of cigarette smoking (803 subjects), cardiopulmonary illness or complaints (382 subjects), other serious illnesses (23 subjects), inability to provide acceptable spirometric manoeuvres (405 subjects), and refusing the offer (470 subjects). The remaining 4,341 cases $(67.6 \%)$ were included in the analysis. The age distribution of the included subjects is presented in figure 2.

In the 342 cases in which duplicate spirometry tests were performed to check interobserver agreement, Bland Altman [15] plots did not disclose a systematic difference between the two systems for the spirometric measurements. Figure 3 illustrates such a plot for FVC. No systematic differences were observed and over $99 \%$ of the differences were $<100 \mathrm{~mL}$.

Table 2. - Derived equations for various spirometric parameters of female subjects

\begin{tabular}{|c|c|c|c|}
\hline Parameter & Equations & $r^{2}$ & SEE \\
\hline \multicolumn{4}{|l|}{$<21$ yrs } \\
\hline FVC $^{\#}$ & $0.03510 \mathrm{H}+0.06651 \mathrm{~A}-3.2230$ & 0.86 & 0.347 \\
\hline Lower limit of normal & $0.0310 \mathrm{H}+0.06651 \mathrm{~A}-3.2230$ & 0.89 & \\
\hline $\mathrm{FEV}_{1}^{\#}$ & $0.02959 \mathrm{H}+0.06588 \mathrm{~A}-2.732$ & 0.87 & 0.296 \\
\hline Lower limit of normal & $0.0260 \mathrm{H}+0.06588 \mathrm{~A}-2.732$ & 0.89 & \\
\hline FEV $1 / F V C \%$ & $-0.0313 \mathrm{H}+0.184 \mathrm{~A}+90.624$ & 0.02 & 2.96 \\
\hline Lower limit of normal & $-0.069+0.184 \mathrm{~A}+90.624$ & 0.15 & \\
\hline PEF & $0.05460 \mathrm{H}+0.16758 \mathrm{~A}-4.86417$ & 0.72 & 1.02 \\
\hline Lower limit of normal & $0.042137 \mathrm{H}+0.16758 \mathrm{~A}-4.86417$ & 0.87 & \\
\hline FEF $25-75$ & $0.027507 \mathrm{H}+0.114723 \mathrm{~A}-2.4084$ & 0.72 & 0.593 \\
\hline Lower limit of normal & $0.021273 \mathrm{H}+0.114723 \mathrm{~A}-2.4084$ & 0.88 & \\
\hline FEF25 & $0.04249 \mathrm{H}+0.184 \mathrm{~A}-3.746$ & 0.76 & 0.84 \\
\hline Lower limit of normal & $0.032 \mathrm{H}+0.184 \mathrm{~A}-3.746$ & 0.88 & \\
\hline FEF50 & $0.031500 \mathrm{H}+0.133505 \mathrm{~A}-2.77412$ & $\begin{array}{l}.00 \\
0.70\end{array}$ & 0.716 \\
\hline Lower limit of normal & $0.023307 \mathrm{H}+0.133505 \mathrm{~A}-2.77412$ & 0.86 & \\
\hline FEF75 & $0.016593 \mathrm{H}+0.060354 \mathrm{~A}-1.52323$ & 0.54 & 0.492 \\
\hline \multirow{2}{*}{\multicolumn{4}{|c|}{$\geqslant 21$ yrs }} \\
\hline & & & \\
\hline FVC $^{\#}$ & $0.04703 \mathrm{H}-0.0246 \mathrm{~A}-3.187$ & 0.59 & 0.381 \\
\hline Lower limit of normal & $0.043 \mathrm{H}-0.0246 \mathrm{~A}-3.187$ & 0.62 & \\
\hline $\mathrm{FEV}^{\#}$ & $0.03715 \mathrm{H}-0.0238 \mathrm{~A}-2.072$ & 0.64 & 0.301 \\
\hline Lower limit of normal & $0.0340 \mathrm{H}-0.0238 \mathrm{~A}-2.072$ & 0.83 & \\
\hline $\mathrm{FEV} 1 / \mathrm{FVC} \%$ & $-0.133248 \mathrm{H}-0.084349 \mathrm{~A}+112.1081$ & 0.08 & 3.964 \\
\hline Lower limit of normal & $-0.181204 \mathrm{H}-0.084349 \mathrm{~A}+112.1081$ & 0.06 & \\
\hline $\mathrm{PEF}^{\#, \oplus}$ & $0.06402 \mathrm{H}-0.0390 \mathrm{~A}-1.607$ & 0.23 & 1.23 \\
\hline Lower limit of normal & $0.051 \mathrm{H}-0.0390 \mathrm{~A}-1.607$ & 0.75 & \\
\hline FEF25-75 & $0.02256 \mathrm{H}-0.0267 \mathrm{~A}+1.242$ & 0.35 & 0.53 \\
\hline Lower limit of normal & $0.017 \mathrm{H}-0.0267 \mathrm{~A}+1.242$ & 0.31 & \\
\hline FEF25 & $0.04925 \mathrm{H}-0.0331 \mathrm{~A}-0.0920$ & 0.23 & 1.03 \\
\hline Lower limit of normal & $0.039 \mathrm{H}-0.0331 \mathrm{~A}-0.0920$ & 0.65 & \\
\hline FEF50 & $0.027839 \mathrm{H}-0.023144 \mathrm{~A}+1.156612$ & 0.21 & 0.71 \\
\hline Lower limit of normal & $0.018660 \mathrm{H}-0.023144 \mathrm{~A}+1.156612$ & 0.48 & \\
\hline FEF75 & $0.012142 \mathrm{H}-0.022301 \mathrm{~A}+0.70640$ & 0.32 & 0.448 \\
\hline Lower limit of normal & $0.008039 \mathrm{H}-0.022301 \mathrm{~A}+0.70640$ & 0.70 & \\
\hline
\end{tabular}

FVC: forced vital capacity; FEV1: forced expiratory volume in one second; PEF: peak expiratory flow; FEF25-75: expiratory flow from 25-75\% of the vital capacity; FEF25, FEF50, FEF75: instantaneous expiratory flows at $25 \%, 50 \%$ and $75 \%$ of FVC, respectively; $\mathrm{H}$ : Height in cm; A: age in years; $\mathrm{r}^{2}$ : coefficient of determination; SEE: standard error of the estimate. ${ }^{\#}$ : volumes are in $\mathrm{L} ;{ }^{\circ}$ : flows $\operatorname{are}$ in $\mathrm{L} \cdot \mathrm{s}^{-1}$. 
Table 3.-Derived equations for various spirometric parameters of male subjects

\begin{tabular}{|c|c|c|c|}
\hline Parameter & Equations & $\mathrm{r}^{2}$ & SEE \\
\hline \multicolumn{4}{|l|}{$<21$ yrs } \\
\hline FVC $^{\#}$ & $0.04202 \mathrm{H}+0.09678 \mathrm{~A}-4.322$ & 0.90 & 0.46 \\
\hline Lower limit of normal & $0.0370 \mathrm{H}+0.09678 \mathrm{~A}-4.322$ & 0.91 & \\
\hline $\mathrm{FEV}_{1}^{\#}$ & $0.03569 \mathrm{H}+0.09030 \mathrm{~A}-3.683$ & 0.90 & 0.46 \\
\hline Lower limit of normal & $0.0310 \mathrm{H}+0.09030 \mathrm{~A}-3.683$ & 0.92 & \\
\hline FEV1/FVC $\%$ & $0.011935 \mathrm{H}-0.13572 \mathrm{~A}+88.2983$ & 0.02 & 3.57 \\
\hline Lower limit of normal & $0.101108 \mathrm{H}-0.13572 \mathrm{~A}+88.2983$ & & \\
\hline $\mathrm{PEF}^{\boldsymbol{\pi}}$ & $0.07238 \mathrm{H}+0.246 \mathrm{~A}-7.720$ & 0.81 & 1.26 \\
\hline Lower limit of normal & $0.058 \mathrm{H}+0.246 \mathrm{~A}-7.720$ & 0.91 & \\
\hline FEF $25-75^{\bullet}$ & $0.03310 \mathrm{H}+0.150 \mathrm{~A}-3.523$ & 0.84 & 0.59 \\
\hline Lower limit of normal & $0.0270 \mathrm{H}+0.150 \mathrm{~A}-3.523$ & 0.87 & \\
\hline FEF $25^{\oplus}$ & $0.04621 \mathrm{H}+0.287 \mathrm{~A}-5.082$ & 0.82 & 1.06 \\
\hline Lower limit of normal & $0.034 \mathrm{H}+0.287 \mathrm{~A}-5.082$ & 0.90 & \\
\hline FEF50 & $0.03646 \mathrm{H}+0.1799 \mathrm{~A}-3.8492$ & 0.82 & 0.733 \\
\hline Lower limit of normal & $0.02796 \mathrm{H}+0.1799 \mathrm{~A}-3.8492$ & 0.84 & \\
\hline FEF75 & $0.02376 \mathrm{H}+0.0512 \mathrm{~A}-2.3791$ & 0.70 & 0.488 \\
\hline Lower limit of normal & $0.01917 \mathrm{H}+0.0512 \mathrm{~A}-2.3791$ & 0.85 & \\
\hline \multicolumn{4}{|l|}{$\geqslant 21 \mathrm{yrs}$} \\
\hline FVC $^{\#}$ & $0.05651 \mathrm{H}-0.0252 \mathrm{~A}-4.093$ & 0.52 & 0.53 \\
\hline Lower limit of normal & $0.052 \mathrm{H}-0.0252 \mathrm{~A}-4.093$ & 0.78 & \\
\hline FEV $^{\#}$ & $0.045302 \mathrm{H}-0.02566 \mathrm{~A}-2.78204$ & 0.56 & 0.43 \\
\hline Lower limit of normal & $0.040619 \mathrm{H}-0.02566 \mathrm{~A}-2.78204$ & 0.76 & \\
\hline FEV $1 /$ FVC $\%$ & $-0.0978 \mathrm{H}-0.104 \mathrm{~A}+107.21$ & 0.15 & 3.04 \\
\hline Lower limit of normal & $-0.124 \mathrm{H}-0.104 \mathrm{~A}+107.21$ & 0.36 & \\
\hline $\mathrm{PEF}^{\pi}$ & $0.07759 \mathrm{H}-0.0435 \mathrm{~A}-1.369$ & 0.15 & 1.96 \\
\hline Lower limit of normal & $0.061 \mathrm{H}-0.0435 \mathrm{~A}-1.369$ & 0.19 & \\
\hline FEF25-75 & $0.02625 \mathrm{H}-0.0360 \mathrm{~A}+1.782$ & 0.32 & 0.76 \\
\hline Lower limit of normal & $0.020 \mathrm{H}-0.0360 \mathrm{~A}+1.782$ & 0.47 & \\
\hline FEF 25 & $0.05913 \mathrm{H}-0.0347 \mathrm{~A}+0.280$ & 0.15 & 1.586 \\
\hline Lower limit of normal & $0.04513 \mathrm{H}-0.0347 \mathrm{~A}+0.280$ & 0.21 & \\
\hline FEF50 & $0.03357 \mathrm{H}-0.0301 \mathrm{~A}+1.423$ & 0.19 & 1.0 \\
\hline Lower limit of normal & $0.025 \mathrm{H}-0.0301 \mathrm{~A}+1.423$ & 0.33 & \\
\hline FEF75 & $0.01563 \mathrm{H}-0.0273 \mathrm{~A}+0.582$ & 0.36 & 0.50 \\
\hline Lower limit of normal & $0.011 \mathrm{H}-0.0273 \mathrm{~A}+0.582$ & 0.58 & \\
\hline
\end{tabular}

FVC: forced vital capacity; FEV1: forced expiratory volume in one second; PEF: peak expiratory flow; FEF25-75: expiratory flow from 25-75\% of the vital capacity; FEF25, FEF50, FEF75: instantaneous expiratory flows at $25 \%, 50 \%$ and $75 \%$ of FVC, respectively; H: height in cm; A: age in years; $\mathrm{r}^{2}$ : coefficient of determination; SEE: standard error of the estimate. \#: volumes are in $\mathrm{L}$; 9 : flows are in $\mathrm{L} \cdot \mathrm{s}^{-1}$.

Anthropometrical characteristics of the whole population and the two subgroups are summarised in table 1. Derived equations for the various spirometric parameters, by age grouping, are presented in tables 2 and 3. Comparisons between the means of the predicted values for each spirometric parameter as derived from the equations and the measured values in the control group are presented in table 4 . The equations predicted measured spirometric variables in the control group very well. The only statistically significant difference occurred in PEF for young males and older females. The comparisons of the performance of the current studies equations with those of HANKINSON et al. [14] are shown in table 5. The observed differences for FVC, FEV1, and expiratory flows in subjects aged $\leqslant 20$ were small. For older subjects, the Caucasian equations of HANKINSON et al. [14], on average, predicted FVC values about 150$200 \mathrm{~mL}$ larger than were predicted by equations used in the current study. The average predicted FEV1 values for the older subjects were almost identical.

\section{Discussion}

Lung function is known to vary with ethnicity. It is, therefore, important to establish normative values relevant to the ethnic characteristics of local populations [7, 16]. The current authors used linear regression models to obtain equations for normative lung function values for the Persian population. As in many other studies, the current study found that the most important predictive variables were height and age and linear equations performed satisfactorily.

Different equations were developed for different age groups because the shape of the curves of FVC and FEV1 versus time, show definite change at age 20 yrs (fig. 1). Before age 20 yrs, the parameters increased with age, while after 20 yrs they decreased. In preliminary analyses, equations derived for the whole age range of the population, showed smaller $r^{2}$ than were found with linear equations. It is well known that linear regression equations in this setting will result in discontinuities at the junction of the two equations. In the equations used in the current study, such discontinuities exist at age 20 yrs. Interpretations of tests near age 20 yrs should reflect the uncertainty of the predicted values.

The study population was not randomly selected. In the current study setting of a developing country, using a randomisation scheme to select subjects would likely have resulted in a poor response that would have negatively impacted the external validity of the study. In addition, VAN GANSE et al. [17] found that for lung function measurements, the method of selection, with the exception of using hospital patients, did not appear to influence either the mean values or their ranges. The sample sizes for children aged $\leqslant 6$ yrs $(n=51)$ and for adults aged $>70 \mathrm{yrs}(\mathrm{n}=52)$ are relatively small and the small sample size at the two extremes of age may affect the accuracy of their equations. This is a common problem affecting most published reports. The remaining variability in 
Table 4.-Comparisons between the means and SD of the predicted values for the control group as derived from the equations and the measured values

\begin{tabular}{|c|c|c|c|c|c|c|c|c|}
\hline \multirow[t]{2}{*}{ Parameter } & \multicolumn{4}{|c|}{ Aged $<21$ yrs } & \multicolumn{4}{|c|}{ Aged $\geqslant 21$ yrs } \\
\hline & Measured & Predicted & p-value & Residuals (absolute) & Measured & Predicted & p-value & Residuals (absolute) \\
\hline \multicolumn{9}{|l|}{ Females } \\
\hline $\mathrm{FVC}^{\#}$ & $2.88 \pm 0.90$ & $2.88 \pm 0.84$ & 0.94 & $0.02 \pm 0.21$ & $3.17 \pm 0.55$ & $3.19 \pm 0.43$ & 0.19 & $0.02 \pm 0.35$ \\
\hline $\mathrm{FEV}_{1}^{\#}$ & $2.56 \pm 0.80$ & $2.55 \pm 074$ & 0.64 & $0.01 \pm 0.31$ & $2.78 \pm 0.47$ & $2.79 \pm 0.38$ & 0.49 & $0.01 \pm 0.28$ \\
\hline FEV1/FVC \% & $88.89 \pm 3.08$ & $88.53 \pm 0.40$ & 0.19 & $0.35 \pm 3.05$ & $88.02 \pm 2.73$ & $87.93 \pm 1.12$ & 0.53 & $0.08 \pm 2.54$ \\
\hline $\mathrm{PEF}^{\top}$ & $5.73 \pm 1.95$ & $5.52 \pm 1.54$ & 0.02 & $0.21 \pm 1.01$ & $6.77 \pm 1.28$ & $6.86 \pm 0.64$ & 0.09 & $0.09 \pm 1.1$ \\
\hline FEF25-75 & $3.27 \pm 1.12$ & $3.24 \pm 0.90$ & 0.58 & $0.11 \pm 0.84$ & $3.74 \pm 0.59$ & $3.71 \pm 0.36$ & 0.14 & $0.03 \pm 0.45$ \\
\hline $\mathrm{FEF} 25^{\circ}$ & $5.23 \pm 1.70$ & $5.34 \pm 1.41$ & 0.11 & $0.12 \pm 0.83$ & $6.24 \pm 1.1$ & $6.30 \pm 0.52$ & 0.22 & $0.05 \pm 0.95$ \\
\hline FEF50 & $3.76 \pm 1.29$ & $3.72 \pm 1.03$ & 0.53 & $0.04 \pm 0.75$ & $4.60 \pm 0.74$ & $4.59 \pm 0.34$ & 0.75 & $0.01 \pm 0.67$ \\
\hline FEF75 & $1.77 \pm 0.75$ & $1.76 \pm 0.51$ & 0.77 & $0.01 \pm 0.54$ & $1.71 \pm 0.51$ & $1.72 \pm 0.28$ & 0.69 & $0.01 \pm 0.40$ \\
\hline \multicolumn{9}{|l|}{ Males } \\
\hline $\mathrm{FVC}^{\#}$ & $3.31 \pm 1.42$ & $3.32 \pm 1.34$ & 0.74 & $0.01 \pm 0.39$ & $4.68 \pm 0.74$ & $4.64 \pm 0.56$ & 0.11 & $0.04 \pm 0.53$ \\
\hline $\mathrm{FEV}_{1}^{\#}$ & $2.94 \pm 1.27$ & $2.92 \pm 1.17$ & 0.319 & $0.28 \pm 0.23$ & $4.05 \pm 0.63$ & $4.01 \pm 0.50$ & 0.03 & $0.04 \pm 0.41$ \\
\hline FEV1/FVC \% & $88.88 \pm 3.14$ & $88.28 \pm 0.36$ & 0.012 & $0.59 \pm 3.19$ & $86.76 \pm 3.24$ & $86.55 \pm 1.24$ & 0.14 & $0.21 \pm 2.95$ \\
\hline $\mathrm{PEF}^{\top}$ & $6.56 \pm 3.21$ & $6.51 \pm 2.65$ & 0.63 & $0.05 \pm 1.54$ & $10.58 \pm 2.49$ & $10.28 \pm 0.85$ & 0.01 & $0.29 \pm 2.32$ \\
\hline FEF25-75 & $3.71 \pm 1.65$ & $3.55 \pm 1.41$ & 0.08 & $0.50 \pm 0.45$ & $4.94 \pm 0.82$ & $4.93 \pm 0.52$ & 0.61 & $0.02 \pm 0.67$ \\
\hline FEF25 & $5.73 \pm 2.52$ & $5.74 \pm 2.25$ & 0.89 & $0.01 \pm 1.14$ & $9.09 \pm 1.8$ & $9.11 \pm 0.66$ & 0.90 & $0.01 \pm 1.7$ \\
\hline FEF50 & $4.06 \pm 1.76$ & $4.07 \pm 1.58$ & 0.88 & $0.01 \pm 0.68$ & $6.02 \pm 0.92$ & $6.04 \pm 0.48$ & 0.63 & $0.02 \pm 0.84$ \\
\hline FEF75 & $1.94 \pm 0.97$ & $1.89 \pm 0.74$ & 0.01 & $0.45 \pm 0.48$ & $2.25 \pm 0.60$ & $2.23 \pm 0.38$ & 0.28 & $0.03 \pm 0.47$ \\
\hline
\end{tabular}

Data are presented as mean \pm SD unless otherwise stated. FVC: forced vital capacity; FEV1: forced expiratory volume in one second; PEF: peak expiratory flow; FEF25-75: expiratory flow from $25-75 \%$ of the vital capacity; FEF25, FEF50, FEF75: instantaneous expiratory flows at $25 \%$, 50\% and $75 \%$ of FVC respectively. ${ }^{\#}$ : volume are in $\mathrm{L} ;{ }^{\top}$ : flows are in $\mathrm{L} \cdot \mathrm{s}^{-1}$.

sample sizes across ages did not significantly influence the curve-fitting procedure because the mathematical functions used in the curve fitting were robust and fit over the full range of ages both in one run, and in separate groups.

The good performance of the derived equations on the control group of subjects confirms the robustness of the derived equations. The predicted values in the control group closely resembled their measured values. The differences between the two sets of mean values were not statistically significant $(\mathrm{p}>0.01)$. The only parameters that approached significant difference were peak flows for older males and younger females. Since control group comparisons are not commonly reported, the present authors do not know if these types of differences occurred in previous studies. Many studies have used their study population for such a test and examined plots of the residuals. While this approach is a valuable tool to evaluate the validity of the equations, testing in a separate group is more reliable. It is less popular because of the increased cost and labour.

In agreement with most previous reports, the mean value

Table 5.-Control group comparison between Persian measured values and the Persian and Hankinson prediction equations

\begin{tabular}{|c|c|c|c|c|c|c|}
\hline Parameter & $\begin{array}{c}\text { Persian measured } \\
\text { values }\end{array}$ & $\begin{array}{l}\text { Predicted with } \\
\text { Persian equations }\end{array}$ & $\begin{array}{l}\text { Persian measured } \\
\text { versus predicted } \\
\text { p-value** }\end{array}$ & $\begin{array}{l}\text { Predicted with } \\
\text { Hankinson } \\
\text { equations }{ }^{\#}\end{array}$ & $\begin{array}{l}\text { Persian lower } \\
\text { limit of } \\
\text { normal range }\end{array}$ & $\begin{array}{l}\text { Hankinson } \\
\text { lower limit of } \\
\text { normal range }\end{array}$ \\
\hline \multicolumn{7}{|c|}{ Females aged $>20$ yrs } \\
\hline FVC L & $3.17 \pm 0.55$ & $3.19 \pm 0.43$ & 0.19 & $3.35 \pm 0.34$ & $2.56 \pm 0.41$ & $2.71 \pm 0.31$ \\
\hline FEV1 L & $2.78 \pm 0.47$ & $2.79 \pm 0.38$ & 0.49 & $2.77 \pm 0.35^{\#}$ & $2.30 \pm 0.37$ & $2.23 \pm 0.32$ \\
\hline PEF $\mathrm{L} \cdot \mathrm{s}^{-1}$ & $6.77 \pm 1.28$ & $6.86 \pm 0.64$ & 0.09 & $6.47 \pm 0.48$ & $4.82 \pm 0.59$ & $4.88 \pm 0.40$ \\
\hline FEF25-75 L $\cdot \mathrm{s}^{-1}$ & $3.74 \pm 0.59$ & $3.71 \pm 0.36$ & 0.14 & $3.00 \pm 0.48$ & $2.84 \pm 0.35$ & $1.84 \pm 0.45$ \\
\hline \multicolumn{7}{|c|}{ Males aged $>20$ yrs } \\
\hline FVC L & $4.68 \pm 0.74$ & $4.64 \pm 0.56$ & 0.11 & $4.89 \pm 0.58$ & $3.87 \pm 0.53$ & $4.02 \pm 0.52$ \\
\hline FEV1 L & $4.05 \pm 0.63$ & $4.01 \pm 0.50$ & 0.03 & $3.94 \pm 0.54$ & $3.36 \pm 0.48$ & $3.21 \pm 0.49$ \\
\hline $\mathrm{PEF} \mathrm{L} \cdot \mathrm{s}^{-1}$ & $10.58 \pm 2.49$ & $10.28 \pm 0.85$ & 0.01 & $9.47 \pm 0.81$ & $7.45 \pm 0.76$ & $7.32 \pm 0.67$ \\
\hline FEF $25-75 \mathrm{~L} \cdot \mathrm{s}^{-1}$ & $4.94 \pm 0.82$ & $4.93 \pm 0.52$ & 0.61 & $3.86 \pm 0.71$ & $3.85 \pm 0.49$ & $2.40 \pm 0.65$ \\
\hline \multicolumn{7}{|c|}{ Females aged $<21$ yrs } \\
\hline FVC L & $2.88 \pm 0.90$ & $2.88 \pm 0.84$ & 0.94 & $2.89 \pm 0.91^{\#}$ & $2.28 \pm 0.77$ & $2.31 \pm 0.79$ \\
\hline FEV1 L & $2.56 \pm 0.80$ & $2.55 \pm 0.74$ & 0.64 & $2.58 \pm 0.78^{\#}$ & $2.02 \pm 0.70$ & $2.09 \pm 0.70$ \\
\hline $\mathrm{PEF} \mathrm{L} \cdot \mathrm{s}^{-1}$ & $5.73 \pm 1.95$ & $5.52 \pm 1.54$ & 0.02 & $5.40 \pm 1.61$ & $3.64 \pm 1.38$ & $3.96 \pm 1.30$ \\
\hline FEF25-75 L $\cdot \mathrm{s}^{-1}$ & $3.27 \pm 1.12$ & $3.24 \pm 0.90$ & 0.58 & $3.10 \pm 0.91$ & $2.23 \pm 0.78$ & $2.06 \pm 0.69$ \\
\hline \multicolumn{7}{|l|}{ Males aged $<21$ yrs } \\
\hline FVC L & $3.31 \pm 1.42$ & $3.32 \pm 1.34$ & 0.74 & $3.36 \pm 1.49^{\#}$ & $2.56 \pm 1.23$ & $2.67 \pm 1.30$ \\
\hline FEV1 L & $2.94 \pm 1.27$ & $2.92 \pm 1.17$ & 0.32 & $2.88 \pm 1.25$ & $2.21 \pm 1.10$ & $2.30 \pm 1.10$ \\
\hline PEF $\mathrm{L} \cdot \mathrm{s}^{-1}$ & $6.56 \pm 3.21$ & $6.51 \pm 2.65$ & 0.63 & $6.17 \pm 2.59$ & $4.34 \pm 2.33$ & $4.47 \pm 2.11$ \\
\hline FEF25-75 L $\cdot \mathrm{s}^{-1}$ & $3.71 \pm 1.65$ & $3.55 \pm 1.41$ & 0.08 & $3.19 \pm 1.28$ & $2.57 \pm 1.24$ & $2.01 \pm 0.95$ \\
\hline
\end{tabular}

Data are presented as mean \pm SD unless otherwise stated. FVC: forced vital capacity; FEV1: forced expiratory volume in one second; PEF: peak expiratory flow; FEF25-75: expiratory flow from $25-75 \%$ of the vital capacity; ${ }^{* *}$ : Level of significance set at p $<0.01$ to account for multiple comparisons; ${ }^{\#}: \mathrm{p}>0.05$. All other $\mathrm{p}$-values for comparisons between Persian versus Hankinson predictions are $<0.01$. 
for FVC in the current adult subjects is marginally less than that predicted for Caucasian Europeans or USA Caucasian subjects (table 5) [14]; the predicted values were closer for children and adolescents. In contrast, average measured FEV1 in Persian control subjects of both age groups were essentially identical to that predicted by HANKINSON et al. [14]. The finding of significantly lower FVCs but similar FEV1 values may reflect longer expiratory times in the study by HANKINSON et al. [14].

Racial or ethnic differences in lung function have been frequently reported $[3,5,14]$. FVC and FEV1 in Whites were found to be larger than Chinese and Indians [6]. USA Blacks were also found to have consistently lower lung volumes than Whites [5]. These differences have been explained in terms of several factors, most related to characteristics of body size and shape [6], which might be attributed to a larger trunk. Fat free body mass as an independent variable [18], and a physique factor created by multiplying height by fat-free mass have been reported to explain differences in FVC between athlete and nonathlete whites [19]. It is conceivable that the physique factor is an indicator of respiratory muscle strength, a factor affected by exercise, nutrition, and overall health status, not by lung function alone. Interestingly, in one study, when the effects of poverty were included in the regression model, the effects of race on pulmonary function decreased [20], a finding suggesting that a significant portion of the reported ethnic differences are determined by socioeconomic variables including nutrition [10]. The socioeconomic status of the subjects of the current study could not be reliably determined and the effects of socioeconomic factors could not be analysed.

This study highlights the importance of obtaining normative values for lung function in different populations at intervals. Further studies of lung function in Middle Eastern countries in different communities as well as other ethnic groups may contribute to the understanding of the relative roles of genetic constitution and exogenous influence on lung function development. In the global village, every physician in any part of the world may be faced with members of different ethnic groups and needs to have information about possible physiological differences including pulmonary function.

\section{References}

1. Eaton T, Withy S, Garrett JE, Mercer J, Whitlock RML, Rea HH. Spirometry in primary care practice: The importance of quality assurance and the impact of spirometry workshops. Chest 1999; 116: 416-423.

2. Langhammer A, Johnsen R, Gulsvik A, Holmen TL, Bjermer L. Forced spirometry reference values for Norwegian adults: the bronchial obstruction in Nord-Trondelag Study. Eur Respir $J$ 2001; 18: 770-779.

3. Ghio JA, Crapo RO, Elliot G. Reference equations used to predict pulmonary function. Chest 1990; 97: 400-403.

4. Marion MS, Leanardson GR, Rhoades ER, Welty TK,
Enright PL. Spirometry reference values for American Indian adults: Results from the strong heart study. Chest 2001; 120: 489-495.

5. American Thoracic Society. Lung function testing: selection of reference values and interpretative strategies. Am J Respir Crit Care Med 1991; 144: 1202-1218.

6. Korotzer B, Ong S, Hansen EH. Ethnic differences in pulmonary function in healthy nonsmoking Asian-Americans and European-Americans. Am J Respir Crit Care Med 2000; 161: 1101-1108.

7. Yap WS, Chan CC, Chan SP, Wang YT. Ethnic differences in anthropometry among adult Singaporean Chinese, Malays and Indians, and their effects on lung volumes. Respir Med 2001; 95: 297-304.

8. Rossiter CE, Weill $\mathrm{H}$. Ethnic differences in lung function: evidence for proportional differences. Int J Epidemiol 1974; 3: 55-61.

9. Hnizdo E, Churchyard G, Dowdeswel R. Lung function prediction equations derived from healthy South African gold miners. Occup Environ Med 2000; 57: 698-705.

10. Mukhopadhvay S, Macleod KA, Ong TJ, Ogoston SA. Ethnic variation in childhood lung function may relate to preventable nutritional deficiency. Acta Pediatr 2001; 90: 1299-1303.

11. Seltzer CC, Siegelaub AB, Friedman GD, Collen MF Differences in pulmonary function related to smoking habits and race. Am Rev Respir Dis 1974; 110: 598-608.

12. Ching B, Horsfall PA. Lung volumes in normal Cantonese subjects: preliminary studies (abstract). Thorax 1977; 32: 352-355.

13. American Thoracic Society. Standardization of spirometry, 1994 update. Am J Respir Crit Care Med 1995; 152: 11071136.

14. Hankinson JL, Odencrantz JR, Fedan KB. Spirometric reference values from a sample of the general U.S. population. Am J Respir Crit Care Med 1999; 159: 179-187.

15. Bland MJ, Altman DJ. Statistical methods for assessing agreement between two methods of clinical measurement. Lancet 1986; 1: 307-310.

16. Cotes JE. Lung Function: Assessment and application in medicine. 4th edn. Oxford, Blackwell Scientific Publications, 1979; pp. 347-352.

17. Van Ganse W, Billet L, Ferris BG. Medical criteria for the selection of normal subjects. In: Arcangeli P, Cotes JE, Cournand A, et al., eds. Introduction to the definition of normal values for respiratory function in man. Alghero, Panminerva Medica, 1969; pp. 15-27.

18. Cotes JE, Chinn DJ, Reed JW. Body mass, fat percentage, and fat free mass as reference variable for lung function: Effects on terms for age and sex. Thorax 2001; 56: 839-844

19. Massey DG, Fournier-Massey G. Japanese-American pulmonary reference values: influence of environment on anthropology and physiology. Environ Res 1986; 39: 418433.

20. Harik-khan RI, Fleg JL, Muller DC, Wise RA. The effect of anthropometric and socioeconomic factors on the racial difference in lung function. Am J Respir Crit Care Med 2001; 164: $1647-1654$. 